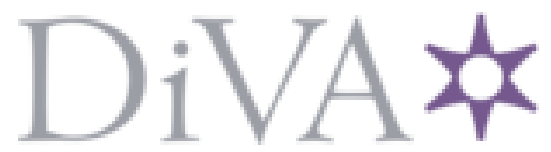

http://www.diva-portal.org

This is the published version of a paper published in Educational Theory.

Citation for the original published paper (version of record):

Johansson, V. (2010)

The Philosophy of Dissonant Children: Stanley Cavell's Wittgensteinian Philosophical

Therapies as an Educational Conversation.

Educational Theory, 60(4): 469-486

https://doi.org/10.1111/j.1741-5446.2010.00371.x

Access to the published version may require subscription.

N.B. When citing this work, cite the original published paper.

Permanent link to this version:

http://urn.kb.se/resolve?urn=urn:nbn:se:du-19220 


\title{
THE PHILOSOPHY OF DISSONANT CHILDREN: STANLEY CAVELL'S WITTGENSTEINIAN PHILOSOPHICAL THERAPIES AS AN EDUCATIONAL CONVERSATION
}

\author{
Viktor Johansson \\ Department of Education \\ Stockholm University
}

\begin{abstract}
Aвstract. Education is often understood as a process whereby children come to conform to the norms teachers believe should govern our practices. This picture problematically presumes that educators know in advance what it means for children to go on the way that is expected of them. In this essay Viktor Johansson suggests a revision of education, through the philosophy of Stanley Cavell, that can account for both the attunement in our practices and the possible dissonance that follows when the teacher and child do not go on together. There is an anxiety generated by the threat of disharmony in our educational undertakings that may drive teachers toward philosophy in educational contexts. Here Johansson offers a philosophical treatment of this intellectual anxiety that teachers may experience when they, upon meeting dissonant children, search for epistemic justifications of their practices - a treatment whereby dissonant children can support teachers in dissolving their intellectual frustrations.
\end{abstract}

The community stagnates without the impulse of the individual. The impulse dies away without the sympathy of the community.

— William James, Great Men and Their Environment ${ }^{1}$

In many educational contexts teachers are identified as communicators and transmitters of the values, skills, and knowledge of a certain community; and children or students are identified as recipients in a practice of being initiated into an acceptance of the givenness of that knowledge and those values and skills. The pedagogical methods and theories that follow from this view may vary. They may emphasize critical dialogue and democratic deliberation, as well as more reproductive views on learning and teaching. In this sense teaching, applying different methods, could be understood as what one might want to call "initiation into practices." However, such a picture of teaching, that we are tempted to think of as following from this characterization of teachers and students, seems to be problematic. A natural way for us to understand this process of teaching and initiation is as a process where the child comes to conform to the rules, norms, or whatever else teachers and adults believe determines their practice as that practice. This picture of teaching presumes that we can know in advance what it means for children to go on the way their educators expect them to.

Stanley Cavell has stressed that, for elders and children to be able to go on together in language, children "have to accept what '[their] elders' say and do as consequential; and [the elders] have to accept, even applaud, what [children]

1. William James, "Great Men and Their Environment," in The Will to Believe, Human Immortality (New York: Dover Publications, 2003), 232. 
say and do as what they say and do. ${ }^{\prime 2}$ This, if it is successful, generates a sort of mutuality that Cavell describes as an attunement between children and their teachers. Nevertheless, this picture contains a sense of anxiety. Nothing can ensure such mutual attunement, and nothing satisfies our (educators') need to secure our knowledge about what it would mean to go on together with the child - that is what the content of such attunement consists in. Cavell recognizes this in his reading of Ludwig Wittgenstein: "Nothing I have said denies that the scene of instruction ends in crisis - there is anxiety over whether the teacher and child will go on together. It strikes me as a crisis of consent. ${ }^{\prime \prime 3}$

We expect children to go on the way we do, but we face situations, real and imagined, that question this expectation. The threat of a crisis of consent intrinsic in our educational practices may cause various reactions: we may force the child to do what we expect, we may become angry and frustrated, we may feel resigned or dejected, we may feel a need to investigate the child's motives or what causes his or her behavior, or we may want to diagnose the child and treat him or her medically. The reaction that I shall further discuss here, a reaction that may cause other reactions, is a kind of philosophical anxiety, a sense of having lost the (epistemic) ground for our practices and identities. This reaction shows that the identification of teachers and students, though useful in some contexts, has limitations when we encounter children that are "out of tune" with how we conceive our practices - children that are dissonant. I shall argue that this anxiety, or sense of crisis, generated by the threat of disharmony in our educational undertakings, can drive us toward philosophy in educational contexts - philosophy as a response to the anxiety that we experience when our identities and practices are questioned by the radically different.

The following famous and often-discussed passage from Wittgenstein's Philosophical Investigations can serve as an example of the dissonant children I consider in this essay, of the crisis of consent Cavell suggests, and of the kind of worry or anxiety we are talking about here:

[A] pupil has mastered the series of natural numbers. Next we teach him to write down other series of cardinal numbers and get him to the point of writing down series of the form

$$
0, n, 2 n, 3 n \text {, etc. }
$$

2. Stanley Cavell, The Claim of Reason: Wittgenstein, Skepticism, Morality, and Tragedy (Oxford: Oxford University Press, 1979), 28. This work will be cited as $C R$ in the text for all subsequent references.

3. Stanley Cavell, Conditions, Handsome and Unhandsome: The Constitution of Emersonian Perfectionism (Chicago: University of Chicago Press, 1990), 76.

VIKTOR JOHANSSON is Visiting Student Researcher at University of Illinois and a Doctoral Candidate of Education at Stockholm University, Department of Education, Stockholm University, SE-106 91 Stockholm, Sweden; e-mail: <Viktor.Johansson@ped.su.se >. His primary areas of scholarly interest are philosophy of education and methods in philosophy of education, philosophy and children's literature, Ludwig Wittgenstein, and Stanley Cavell. 
at an order of the form " $+\mathrm{n}^{\prime}$; so at the order " +1 " he writes down the series of natural numbers. - Let us suppose we have done exercises and given him tests up to 1000 . Now we get the pupil to continue a series $($ say +2$)$ beyond 1000 - and he writes 1000, 1004, 1008,1012 .

We say to him: "Look what you have done!" - He doesn't understand. We say: "You meant to add two: look how you began the series!" - He answers: "Yes, isn't it right? I thought that was how I was meant to do it." - Or suppose he pointed to the series and said: "But I went on in the same way." - It would now be no use to say: "But can't you see...?" - and repeat the old examples and explanations. - In such a case we might say, perhaps: It comes natural to this person to understand our order with our explanations as we should understand the order: "Add 2 up to 1000, 4 up to 2000, 6 up to 3000 and so on."

Such a case would present similarities with one in which a person naturally reacted to the gesture of pointing with the hand by looking in the direction of the line from the finger-tip to wrist, not from wrist to finger-tip. ${ }^{4}$

Wittgenstein's student "naturally reacts" in a way that we find problematic, even absurd, in a way that we do not count as a part of the practice we are engaged in. In addition, the student may insist that his or her reaction is, if not better than, at least equally valid, or equally well founded (or not founded), or even that his or her reaction is the same as his or her teacher's. The possibility of deviant natural reactions that may be conceived as doing what we do when we do not see that ourselves, points toward a very real worry. Somehow, we feel tempted to say to these children that they must do as we conceive ourselves doing. We worry about what will happen when we cannot justify or further explain our practices of, in this case, mathematics and following instructions. We are confused not only because we do not know how to continue our instructions, but also because our ways of doing things are questioned. I therefore refer to dissonant children not only as children whose behavior and reactions to our instructions are deviant and whose behaviors we for some reason find difficult to understand. A dissonant child is a child whose reaction to our instructions causes anxiety and a sense of crisis by, as with the skeptic, questioning the justifiability and explainability of our practices. ${ }^{5}$ Consequently, we can characterize the kind of anxiety that these children may cause as dissatisfaction with our inability to justify our practices and, to use Cavell's formulation, our dissatisfaction with our human condition.

Dissonant children are not unfamiliar to those who have been engaged in educational practices. Most educators have at times been surprised, worried, and had their temper tested, when the children they teach react in unexpected, and

4. Ludwig Wittgenstein, Philosophical Investigations, 3rd ed., trans. G.E.M. Anscombe (Oxford: Blackwell, 1953), 185 (emphasis added). This work will be cited as PI, followed by paragraph number for part I or page number for part II, in the text for all subsequent references.

5. It is not the dissonance or what we find as an unnatural "natural" reaction of the child per se that causes our confusion. There are, of course, many different reactions we find deviant. Not all of them are problematic, and they do not all provoke the same philosophical questions. (For example, there are cases when we can just ask the child why he or she does things a particular way and get a clear answer and cases where the deviancies in children's behaviors do not end in crisis. These children do not cause the same sense of crisis.) Our reaction in meeting Wittgenstein's student and similar scenes of instruction is quite different. In these instances we are unable to accept the child's way of doing things. 
at times provocative, ways to their instructions, teaching, training, or examples. The teachers may, consciously or unconsciously, be inclined to ask certain types of philosophical questions, such as the following: How can we justify and explain our way of talking, thinking, reading, writing, acting, making moral judgments, and the like? In short, how can we justify and explain our form of life so that these children react the way we do? Can we justify our exclusion and inclusion of certain behaviors?

Instead of giving a straight answer to these questions, educators can, analogous to Wittgenstein's response to skepticism and metaphysics, "turn their investigation around" (see PI $§ 108$ and 309). To look for a straight answer would be to give heed to the illusion that we have lost the foundation for our practices, when in fact nothing has been lost. Instead, we need to "therapeutically" treat our worry about the possibility of dissonance, be satisfied by the groundlessness of our practices, and rediscover our ordinary practices. These questions cannot be answered by theorizing, but rather responded to by becoming at ease with the conditions of our humanity. Philosophy in educational contexts can in this sense be a practical struggle. My methodological claim is that philosophy can be used as a particular approach by teachers, to treat their own intellectually frustrated reactions to dissonant children. The conversations with children, or "education for grown-ups" as Cavell puts it, I recommend is not a guide for how teachers should act, but rather an indication for the need of diagnosis - implying that our thinking might show symptoms of an existential illness - and therapeutic treatments of some educational issues philosophically — implying that, though there might be no definite cure, there are at least treatments. The practicality of the method lies in the treatment of the issues discussed as existential conflicts rather than didactic problems. I shall argue that these are insights that we can arrive at if we apply the philosophical works of Wittgenstein and Cavell to educational contexts involving dissonant children. Furthermore, this will show that Wittgenstein and Cavell's writings are pedagogical in a practical sense.

This pedagogical practicality of the Wittgensteinian philosophical approach may be applicable to our approach to dissonant children in many ways. Here I shall concentrate on the philosophical (skeptical) anxiety of the educator. This investigation will thus be limited to questions about what kind of approaches to take toward children that follow from this, and the motives or sources of the child's behavior will have to be investigated in another text. In a sense, this may mean that children's voices seem silenced in giving room to their elders' (philosophical) reactions - for example, the reasons and causes for children's dissonant behavior may not be asked for or stated. However, here my aim is rather to provide a method for the educator to actually hear and listen to the voices of dissonant children, see the value of dissonance, and perhaps even hear the beauty in the disharmony; this, being an education for grown-ups, means relearning how to listen (as we must to appreciate the great composers of the last century such as Schönberg, Stravinsky, Stockhausen, and others). This investigation is thus preliminary to further exploration of the reasons for and causes of children's dissonant behavior. 
The aim of this sort of philosophizing is thus to give teachers, parents, educators, and educationalists philosophical tools to go on with their children. It is to enhance teachers' (or adults') imagination by helping them to reconsider their lives with dissonant individuals. The investigation thus aims to show how teachers, by letting themselves be inspired by dissonant children, by taking an interest in those children, can transform themselves and their cultures. ${ }^{6}$

First, I shall discuss Wittgenstein's vision of language, and how Wittgenstein's examples of dissonant children elucidate the fact that meaning cannot be determined by anything other than our use of expressions. Second, I shall argue for an understanding of the notion "form of life" in Cavell and Wittgenstein that is both social and biological. Third, I maintain that the actuality and possibility of dissonant children illuminates how skepticism is an existential condition of our human form of life and of our educational practices in particular, which elucidates how dissonance may seem threatening. Fourth, I shall argue that educators, following Wittgenstein and Cavell, need to use a kind of philosophical therapy to treat this anxiety. This involves a reconsideration of our reactions to radically different (dissonant) children: ${ }^{7}$ we can meet them as we read philosophical texts, and let them serve as teachers, that is to say, let their teachers become students.

\section{Wittgenstein's TerRifying Vision of LANGUAGe}

A fairly common view - it might even be called traditional ${ }^{8}$ — among philosophers and philosophers of education is that Wittgenstein claimed that language is an essentially normative practice and that linguistic meaning is determined by how words are used according to implicit norms or even explicit rules. An early example of this interpretation is David Pole's The Later Philosophy of Wittgenstein, which was criticized by Cavell in one of his earliest writings on Wittgenstein. This critique is quite useful in conceptualizing an alternative Wittgensteinian vision of language that can better account for the threat of dissonance in educational contexts. We can, following Cavell, summarize Pole's (or the traditional) view in two statements:

1. The correctness or incorrectness of a use of a word is determined by the rules of a language-game in two ways: First, the rules of language form a system, which makes it obvious where and when a rule does or does not apply. Second, when rules apply, it is obvious whether they are being followed or violated.

6. Stanley Cavell, Philosophy the Day After Tomorrow (Cambridge, Massachusetts: Belknap Press of Harvard University Press, 2006), 121-122.

7. I will use the term "children" even though this does not only apply to young children. In fact many of the instances I had in mind while working on these issues involve adolescents as well as young children.

8. James Conant, "Wittgenstein on Meaning and Use," Philosophical Investigations 21, no. 3 (1998): 223. 
2. When new linguistic practices are created and no existing rules apply, we create new rules, and this changes the language-game. ${ }^{9}$

I maintain that this view of language fails, both as a reading of Wittgenstein and as a fruitful philosophical position. Rather, Wittgenstein's investigations of the concept "rule" show that language is not everywhere circumscribed by rules (PI $\S 68$ ). In fact one of the conclusions in Wittgenstein's infamous paragraphs on rule-following is that if understanding a language consists in grasping and following its rules, we can always ask what a correct application, or interpretation, of those rules consists of when we apply the rules to further cases (PI § 201). ${ }^{10}$ If language, or any human practice, is in need of an explanatory justification (a foundation) by appeal to rules or anything else, we will end up with a paradoxical view of language where further explanations will always be required. Of course, this does not imply that rules or similar phenomena have no role in our linguistic practices. It simply means that they cannot play the role of satisfying our urge to construct a secure epistemic foundation for our language use, and that they do not (except in some special cases) determine meaning. Nevertheless, we are tempted to say that there has to be something that determines the meaning or ensures that we express ourselves meaningfully. This is because we are held captive, as Wittgenstein claimed, by a way of thinking and speaking (PI $\S 115)$. This captivating picture entails the idea that as long as we follow some general principle, we can make ourselves understood; that meaningfulness in expressions is outside the speaker's control. Questioning this is to question any form of theory that aims to justify our use of linguistic expressions. This critique is essential to Wittgenstein's antifoundationalism. It is not just a critique of traditional foundationalist arguments of justification of knowledge and our praxis, but a critique directed toward any attempt to justify our practices that thus includes antirealist arguments in its critique. Cavell suggests an acceptance of the fact that nothing ensures that a particular use of a word is correct or incorrect. But what does it mean to say that nothing determines linguistic meaning, and how can this be understood in the example of the dissonant child?

It can be said that Wittgenstein, in his later philosophy, extended Frege's principle that a word only has meaning in the context of a proposition, applying it not only to words, but to sentences, which accordingly will have meaning only in the context of a language-game (that is, the context of significant use). ${ }^{11}$ Sentences have meaning only in the context of how they are used within language-games (PI $\S 43$ ). Hence, what constitutes our meaning something by uttering a sentence is

9. Stanley Cavell, "The Availability of Wittgenstein's Later Philosophy," in Must We Mean What We Say? 2nd rev. ed. (Cambridge: Cambridge University Press, 2002), 47-48.

10. See also Ludwig Wittgenstein, The Blue Book and the Brown Book: Preliminary Studies to the Philosophical Investigations (Oxford: Basil Blackwell, 1958), 27-28.

11. Conant, "Wittgenstein on Meaning and Use," 231-238. See also Gottlob Frege, The Foundations of Arithmetic: A Logico-Mathematical Enquiry into the Concept of Number (Evanston, Illinois: Northwestern University Press, 1980), x. 
not that the uttering is followed by some other process - for example, a mental representation, a rule or norm, or a universal - but that it is used in a context where it can do the grammatical work of meaning something. ${ }^{12}$ Instead of giving in to our temptation to treat a word as if there was "an atmosphere accompanying the word, which it carries with it in every application" (PI § 117), we need to remind ourselves that a sentence makes sense only in the context where it is actually used. An expression does not have meaning by itself. The responsibility for success in meaning something by our words lies solely with the communicators, with us.

This poses further difficulties for the assumption that language is essentially normative. The difficulty is due to a misunderstanding of what it means to "project a word," or sentence, into new contexts. When introducing words in new contexts or creating new language-games, the "normative" view implies that the words of such a justification (by referring to rules) cannot be given a clear meaning. The rules of this new language-game are nonsense because the rule-expressions are excluded from language (compare with PI $\S 500$ ), not because of the rule-expression itself, but because the speaker fails to do anything meaningful with this rule-expression within an existing language-game (when rules are changed or created, they are always changed within an existing language-game.) Since an analogous difficulty will evolve if we replace rules with anything else determining meaning, we have to conclude that nothing determines meaning and in this sense acknowledge a form of meaning skepticism. Cavell illustratively writes,

\begin{abstract}
We learn and teach words in certain contexts, and then we are expected, and expect others, to be able to project them into further contexts. Nothing insures that this projection will take place (in particular, not the grasping of universals and not the grasping of books of rules), just as nothing insures that we will make, and understand, the same projections. That on the whole we do is a matter of sharing routes of interest and feeling, modes of response, senses of humor and of significance and of fulfillment, of what is outrageous, of what is similar to what else, what a rebuke, what forgiveness, of when an utterance is an assertion, when an appeal, when an explanation - all the whirl of organism that Wittgenstein calls "forms of life." Human speech and activity, sanity and community, rest upon nothing more, but nothing less, than this. It is a vision as simple as it is difficult, and as difficult as it is (and because it is) terrifying. ${ }^{13}$
\end{abstract}

We still might want to ask, how is this possible? Can't we explain to Wittgenstein's student that he is wrong in claiming that he is following his teacher's instruction? Is there no way we may be justified in saying that the student's projection of the rule "add 2 " in PI $\S 185$ is wrong? Put differently, dissonant children such as Wittgenstein's student tempt us to ask questions such as this: Isn't there a way to justify and explain our linguistic and cultural practices? We may then be tempted to ask skeptical questions: But if nothing determines what I mean by my expressions (or how I use them), how then am I able to mean something determinate at all? Or, how can I know what anyone, myself included, means by saying "add 2"? The temptation to ask these sorts of questions, and our incapacity to be satisfied with any answers to them, is what

12. Conant, "Wittgenstein on Meaning and Use," 239-240.

13. Cavell, "The Availability of Wittgenstein's Later Philosophy," 52. 
Wittgenstein and Cavell, through using dissonant children in their accounts, want us to recognize $(C R, 175)$. This is supposed to lead to a criticism and investigation of our "language and conduct" and our philosophical presumptions that is not moralistic. We need methods, when we reach the justificatory bedrock, to convert ourselves to satisfaction; and to recognize that our inclination may be to say to our children, "This is simply what I do" (PI $\S 217)$, as if this is what the child must do. This does not mean that we should not correct the child in $\S 185$, but rather it raises the question of on which grounds we can carry out such corrections and helps us realize what we are inclined to think in such situations. ${ }^{14}$ Our inclination to say "This is simply what I do" seems to mark the need for the teacher to be willing to present him- or herself as an example for the community into which the child is being invited. The inclination marks that this is not a matter of saying "Do as I do, or else!" but a realization that our best option seems to be to simply rely on our own examples. ${ }^{15}$

The student in $\S 185$ clearly does not know, or refuses to play, the languagegame of writing down a series as we do. Hence, if we want to say about him that he does what we do, we must teach him this language-game. "Teaching would here be something like 'showing them what we say and do', and 'accepting what they say and do as what we say and do', etc.; and this would be more than we know, or can say" $(C R, 178)$. This teaching, call it initiation into our "form of life" (we will return to this notion later), involves both us showing the child what we do and how we react and act in certain circumstances (we are an example), and a response from the child that we are able to call "following an instruction." Hence, the question about what determines meaning is a matter of how we teach and what we count as learning to do what we do just as much as it is a matter of children's responses to our instructions. In a sense, it is a matter of self-knowledge - knowledge of what we count as belonging to our "we" - to our linguistic community. What we search for is a knowledge about what we count as "appropriate projections of words and concepts into further contexts" when any projection is possible.

Still, it is a frightening fact that nothing ensures that we will be understood when we project a word into a new context. Nevertheless, this is a necessary condition for language to work the way we want it to. There are always new conditions to be met, new objects, new perceptions and relationships, and this means that the learning of language is never complete. We continuously develop language and our linguistic capacities. If language were closed by something final, determining meaning, this open-endedness in language acquisition would not be possible. It means that our concepts in ordinary language may have "blurred" edges $(P I \S 70)$, which is what Wittgenstein's game analogy is supposed to elucidate.

Wittgenstein maintained that we call many different activities "games," including board games, card games, ball games, Olympic games, children playing with a ball, and so on. Instead of being captivated (and held captive) by our picture

14. Cavell, Philosophy the Day After Tomorrow, 204.

15. Cavell, Conditions Handsome and Unhandsome, 72-73. 
of games, presuming that there must be something in common for everything we call games, Wittgenstein exhorts us to look and see (PI § 66). When we "look" at the different contexts in which the word "game" is projected, we find that there is not one feature common to all of them. Rather the similarities can be characterized as "family resemblances" (PI § 67). The phenomena we call "games" are like members in a family where some share the same color of eyes, others the size of feet, others certain dispositions, and so on. Language is in this sense inclusive and tolerant to variation. On the other hand, language (that is, our ordinary language), in this view, is equally intolerant to variations. By projecting "game" into some contexts and not others, we exclude possible projections of a word from our practice. ${ }^{16}$

These two aspects are brought to our attention when we consider children's dissonant reactions to their teachers' instructions or questions. For example, the student in $\S 185$ does not respond to his teacher in a way that we could accept as following the instruction. We would even say that he does not understand the instruction. However, we can, if we try, understand the student's expressions. We can recognize a pattern in how the student continues his series, and we can interpret his response and with a little effort explicate what he is doing. This would not be possible if rigid limits, like rules or universals, determined ordinary language use. Because of the "tolerance principle," we understand the student's behavior, and because of the "intolerance principle," we do not count his response as following the instruction he was given. We admit that we can say to the student: "I understand what you're writing [we take the student's words to be our words], but I can't see your point (the point, say, of writing it now, or of saying it to me, or of saying it like that): that is to say I can't understand you." 17 That is to say, we would understand these words in another context, but we do not understand what

16. Wittgenstein gives an illustration of how tolerance is a condition for language to work for us in $P I$ $\S 107$. To show how philosophers tend to require language to be "crystal clear" and fit into our views of logic, he wrote, "We have got on to slippery ice where there is not friction and so in a certain sense the conditions are ideal, but also, just because of that, we are unable to walk. We want to walk; then we need friction" (my translation; following Cavell I prefer translating "dann" as "then" instead of, as in Anscombe's translation, as "so"). We need the friction of not being completely comprehendible to each other - which is a result of the tolerance principle - to be able to comprehend each other at all. This kind of analogy is fruitful since the principles of tolerance and intolerance are called for when we are uncertain of our abilities and willingness to go on together. To be able to walk together, we must realize our need to walk together and be willing to walk together in moments of opposition. If we want to go on together, we need "rough ground" and the threat of incomprehensibility, since the ice of ideal linguistic conditions makes it impossible to comprehend dissonant individuals who do not speak ideally. If we want to walk with them, then we need to accept the friction of such a walk. (The change of the connective ["so" to "then"] is an indication that what is at work here is a Wittgensteinian turning of the examination around our real need [PI § 108]). See Stanley Cavell, This New Yet Unapproachable America: Lectures after Emerson after Wittgenstein (Albuquerque, New Mexico: Living Batch Press, 1989|, 55-56. This work will be cited as UA in the text for all subsequent references. This thought developed in conversation with Gabriel Sandberg and as a response to clarifications asked for by an anonymous reviewer.

17. Avner Baz, "On When Words Are Called For: Cavell, McDowell, and the Wording of the World," Inquiry 46, no. 4 (2003): 483. 
the student is doing now $(C R, 215)$. In a very ordinary manner the student brings to light the grammar (criteria) of our language-game of writing a series of cardinal numbers. Having done this, we are in a position to, as Wittgenstein did with our traditional "philosophical language-games," examine the point of such games. Do we really do what we want to do, and believe we do, with these games?

For Wittgenstein the point of introducing dissonant children in this discussion is twofold. First, the intention is to elucidate how dissonant children draw our attention to the grammar of our language-games. Hence, the philosophical problem of justifying our linguistic practices and creating determinate theories of meaning transforms into a practical problem of recognizing the everyday uses of our words, or our everyday practices. The dissonant child provides a way for us (philosophers and adults) to turn our investigation toward the everyday uses of language. If we let them, dissonant or radically different children can elucidate important aspects of ourselves. Second, dissonant children elucidate the "terrifying" fact that there is always a possibility that we do not understand one another. This reminds us of, and forces us to acknowledge, the groundlessness of our language-games and the possibility of the "crisis of consent" that is intrinsic in educational practices. Nothing ensures that instructions will be followed in the way teachers expect and desire.

\section{Our Human Forum of Life}

What does it mean that we agree in our use of words, or, as Cavell puts it, that "we agree in all the whirl of organism that Wittgenstein calls 'forms of life" "? We have seen that Cavell refers to our agreement, or our "attunement," as an element of our form of life, of us "sharing routes of interest and feeling, modes of response, senses of humor and of significance and of fulfillment," and so on. Wittgenstein says that "what has to be accepted, the given, is ... forms of life" (PI II, 192). What has to be accepted is, if I understand, our humanity. It has been suggested that this notion, form of life, is the pedagogical notion in Wittgenstein. ${ }^{18}$ One may wonder, then, what is this human form of life that we share?

There are two primary directions taken by the interpretations of Wittgenstein's text that reveal different tendencies in understanding the notion. I label these directions the social interpretation and the natural interpretation. Both of these fail to account for what Wittgenstein seems to have meant by "form of life." This is clear when we consider how we understand recalcitrant children. The failure of these accounts reveals a tendency in our theorizing about radical difference.

The social interpretation emphasizes the idea that form of life is something children are initiated into. Philosophers of education such as Paul Smeyers and James Marshall have argued that "this initiation is quite evidently socially

18. Paul Smeyers and James Marshall, "The Wittgensteinian Frame of Reference and Philosophy of Education at the End of the Twentieth Century," in Philosophy and Education: Accepting Wittgenstein's Challenge, ed. Paul Smeyers and James Marshall (Dordrecht: Kluwer Academic, 1995), 17. 
sanctioned." To be a part of the human form of life is, according to Smeyers and Marshall, to be "grasped in human order."19 This, however, would mean that there is a tension in Wittgenstein that is speaking through Smeyers and Marshall. Our form of life would be what is given and determined by our social sanctions of each other's behavior. The idea of social sanctions that govern our social practices or our form of life seems to be incompatible with Wittgenstein's idea that there is nothing that determines what counts as doing what we do.

The natural interpretation emphasizes the biological aspect of humanity. What is given, and what has to be accepted as what determines our possible ways of speaking and acting, is our nature as biological creatures. It is reasonable to say that our biologically determined practices lie beyond justification and further explanation. This interlinks "form of life" with other important notions in Wittgenstein such as "natural reaction" and "natural history." Our form of life in this sense consists of the capacities and reactions that humans have in common. The language-games we play and the social practices we are engaged in are a result of our natural history - the history of what we have done in the past - and our natural reactions - our reception of these past activities in the present $(P I \S 25$, compare with $\S 415)$. Whether or not we can play a language-game, of the past or one created in the present, is a matter of social and individual contingencies rather than the necessities of what is given in our form of life.

However, the recital of $\S 185$ reveals a different aspect of the notion. Wittgenstein compares the student's reaction to that of "a person [who] naturally reacted to the gesture of pointing with the hand by looking in the direction of the line from the finger-tip to wrist, not from wrist to finger-tip." Would this mean that, just as in the social interpretation of "form of life," a person that does not conform to the structures of a given social order cannot be grasped in human order, or as in the natural interpretation, a child who does not share our natural reaction is not fully human?

So, even though forms of life as our natural history and natural reactions are given, we can deny them or fail to share them with others. What then are the common factors in our form of life? It is quite obvious that the differences between our different practices and language-games are important to Wittgenstein (see, for example, PI $\S 130,290$, and 304). Human (linguistic) activities do not always work the same way or have the same purpose. This is a condition given in the human form of life. ${ }^{20}$ Still, the natural reaction of the student in $\S 185$ is a reaction that, if it is natural, he ought to share with us, but that he does not. The actual possibility of dissonance makes it difficult to understand this interpretation of Wittgenstein's notion.

19. Ibid., 9 and 17.

20. Newton Garver, This Complicated Form of Life: Essays on Wittgenstein (Chicago: Open Court, 1994), 266. 
The problem with these understandings of "form of life" is that dissonant children, or their reactions, do not always fit into our preconceptions of what a natural or social human reaction is. One could say that the problem arises because of our natural tendency to misunderstand radical difference. Further, one could question how any notion of something that is given, and must be accepted, is reconcilable with the principles of tolerance in our linguistic practices. In addition, how shall we understand the possibility of dissonance if we must accept our forms of life as something given? There appears to be a "must" in the idea that we only accept each other's behavior as long as we share the same natural reactions or socially trained behavior. This is the essential problem for both the natural and the social interpretation of "form of life." We try to resolve our uneasiness in facing the dissonant child by seeking such a "must," but whatever is taken as such a "must" faces the possibility of dissonance as well and is subject to the same kind of uneasiness.

Cavell has described this sense of being uneasy as being lost, as "a loss of self-knowledge" $(U A, 36-37)$. And Wittgenstein claims, "A philosophical problem has the form I don't know my way about" (PI $\S 123)$. The therapy we need in order to resolve our uneasiness ought to bring us back where we "find our way around"; to a place where we are not worried; as Wittgenstein put it, to a homeland. Instead of persisting in using words to articulate the "musts" we use in philosophical reasoning, or as a response to dissonant children and radical difference, Wittgenstein exhorted us to ask ourselves, "Is the word ever actually used in this way in the language which is its original home?" And about his own philosophical methods, he said, "What we do is to bring our words back from their metaphysical use to their everyday use" (PI 116$).{ }^{21}$ For Cavell, the philosophical confusion that we find ourselves lost in cannot only be remedied by bringing our words back, but also by bringing our lives back to the ordinary $(U A, 35)$. I claim that, instead of leading us astray, the dissonance in children's behavior can, if we let it, elucidate our ordinary practices, our homeland.

This "therapy" offered by and for our meetings with dissonant children as a part of our form of life coincides with Cavell's treatment of philosophical skepticism. The sense of being lost in the face of radical difference is analogous to the threat epistemologists find in skeptical narratives. The skeptical and dissonant threat lies in the questioning of our intellectual and social practices. Dissonant children

21. There is an apparent tension with what I said earlier regarding Cavell's idea of projecting words into new contexts. One may ask, "Why is it necessary to 'bring our words back' when we make philosophical projections of words such as 'knowledge,' 'being,' 'object,' 'I,' or even 'form of life'?"' However, this tension is only apparent. The difference between the "philosophical" projections of these words and other new projections is that the philosophers (epistemologists) fail to do what they aim to do with their projections. The philosopher who searches for the essence of a concept will constantly fail to project the word into a meaningful context. Nonetheless, it is important to recognize that these kinds of philosophical projections are always possible, even with Wittgenstein's own expressions, which means that there is no final solution of the problems of philosophy. The philosophical battle against language is a part of our human condition. The issue is rather about which attitude we should take toward this possibility. 
make us aware that the common understanding of our form of life, or idea of what is human, fails. Our problem is our inability to be satisfied with the fact that we cannot once and for all define concepts such as "form of life" and "human." If these misconceptions of the notion of "form of life" are due to philosophical uses of the notion, what then is the "original home" of the notion? Given the tolerance and intolerance principles, there is no distinguishable unchangeable use of any term. Every concept can be projected into new contexts. This is true of many of the technical key concepts of the Investigations, such as "form of life." Since it is our, or even and especially my, worries and sense of being lost that are being treated, I can only make use of Wittgenstein's "therapies" as long as I make his concepts my own (which is one reason, I believe, why Wittgenstein was so cautious about not defining many of his key concepts). This is important because any definition and explanation of a concept can be dissatisfying for us, since that will exclude some applications of the concept. In the original home of "form of life," as Wittgenstein used the term, "there are no criteria for what does exhibit a form of life" $(U A, 43)$. Thus, it is important that the term can be interpreted both in the natural and the social direction. According to Cavell, there are both "ethnological and ... biological directions or perspectives encoded in the phrase." 22 Given that "grammar tells what kind of object anything is" (PI $\S 373$ ), and that there is no clear grammar for what exhibits a "form of life," the responsibility for how to use the notion in a way that avoids losing ourselves in philosophical confusion lies with us. We can shape the grammar or criteria of the concept "form of life." Because it is our form of life, we also shape life itself, and we hold the responsibility for the effects of doing so. This should not be understood as a form of relativism. We are responsible for our form of life not because we have reasons for living this life rather than other possible forms of life, but because it is our form of life, it consists of our lives. Our form of life cannot serve as an epistemic foundation justifying our practices. Rather, form of life is our practices, what and who we are, our natural history and our present sociality; and this is supposed to treat our need for, and dissatisfaction with, epistemic justifications.

Taking this responsibility, Cavell recognizes that "it is inconvenient to question a convention, that makes it unserviceable, it no longer allows me to proceed as a matter of course; the paths of action, the paths of words are blocked" $(C R, 125)$. Dissonant children are asking such inconvenient questions, and our tendency to answer them by referring to things other than ourselves - our actual practices or use of words - is what drives us toward skepticism. Additionally, dissonant children threaten our very nature and understanding of ourselves as human. Of course we, as teachers, parents, and elders, feel lost in such situations. Regardless, even though the questions as such might drive us to speak nonsense, they are important, and dissonant reactions are elucidating. Commenting on

22. Stanley Cavell, "Notes and Afterthoughts on the Opening of Wittgenstein's Investigations," in Philosophical Passages: Wittgenstein, Emerson, Austin, Derrida (Oxford: Blackwell, 1995), 158; and Cavell, This New Yet Unapproachable America, 41-42. 
$\S 19$ of the Investigations — "to imagine a language means to imagine a form of life" - Cavell writes,

In philosophizing, I have to bring my own language and life into imagination. What I require is a convening of my culture's criteria, in order to confront them with my words and life as I pursue them and as I may imagine them; and at the same time confront my words and life as I pursue them with the life my culture's words may imagine for me: to confront the culture with itself, along the lines in which it meets me.

This seems to me a task that warrants the name of philosophy. It is also the description of something we might call education. In the face of the questions posed by Augustine, Luther, Rousseau, Thoreau..., we are children; we do not know how to go on with them, what ground we may occupy. In this light philosophy becomes the education of grown-ups. $\mid C R, 125$, emphasis added)

This education for grown-ups is a matter of recognizing not only our everyday linguistic practices (use of words), but also of recognizing our humanity, our form of life. Our words, thoughts, and practices are a part of the human form of life and that is the context in which they are significant. It is not a matter of avoiding the philosophical questions that we are provoked to reflect upon by dissonant children; quite the opposite. These questions are a part of our human form of life but we do not need to answer them. Rather we ought to use them to rediscover our educational culture and our educational form of life. As Cavell puts it, "The anxiety in teaching, in serious communication, is that I myself require education. And for grown-ups this is not natural growth, but change" $(C R, 125)$. In investigating the concept "form of life," this is what we should do. We should bring our culture and our understanding of ourselves into imagination by bringing our form of life into imagination. Nonetheless, we treat dissonant children as skeptics who question our practice. In meeting them, we want our practices to take the responsibility of being meaningful and significant. This is a struggle with our human condition, a condition that we persistently try to transcend by arguing with skeptics or children (UA, 56-57).

\section{DissonanCe AND SKepticism}

That we agree in forms of life does not mean that everyone is performing identical actions (what would that mean anyway?), but rather that what is done is accepted as what we do. Wittgenstein claimed that "it is what human beings do say that is true and false; and they agree in the language they use. That is not agreement in opinions but in form of life" (PI $\S 241)$. Cavell's interpretation of the German original is clearer. In the German text, Wittgenstein wrote "Übereinstimmung" in place of "agreement" and "in der Sprache stimmen die Menschen überein" instead of "agree in the language they use." "Stimmen" can also be translated as "attune," as in tuning a musical instrument $(C R, 31-32)$. "Attunement," however, does not suggest the same conformity as "agreement" does. Musical attunement is more a harmony between different voices - a chord or a melody requires more than one voice, pitch, or length of tone that can be recognized as part of the same tune, chord, or melody, as well as heard as distinctly different.

In suggesting that skeptical worry is a human condition, Cavell directs our attention to the fragility of our attunement. As has already been pointed out, and as 
evident when considering dissonant children, nothing ensures that we will share the same reactions or that we call the reactions we share by the same name. It is equally important to recognize that we sometimes are out of tune, in dissonance $(C R, 32)$. This means that even though we might not believe the skeptic, in a sense we live skepticism, since in our form of life skeptical reasoning will always be a threatening possibility - it is a picture that is repeated in our forms of language. According to Espen Hammer, this means that "scepticism should be viewed less as an intellectual problem than as an existential challenge or temptation, one which rationalizes a standing threat to our attunement; and as such it needs to be elucidated and explained, in short, acknowledged rather than refuted."'23 In this sense, the child of $\S 185$ illustrates the truth of skepticism by not sharing our reactions or by playing out of tune; and we may need to reform our conception of harmony in order to be able to hear the beauty of dissonance instead of trying to avoid it. Learning can be understood both as when a child accepts what the teacher does and when a teacher acknowledges what a child does. Given that we can acknowledge dissonant children's reactions, we can conceive dissonant children as geniuses or disobedient sensibilities instead of merely as problems we have to deal with. Cavell exemplifies this through his discussion of Henry David Thoreau: "Thoreau calls himself disobedient, but what he means is not that he refuses to listen but that he insists on listening differently while still comprehensibly. He calls what he does revising (mythology)" $(U A, 44)$. The child becomes a teacher of the new culture that we are transforming toward.

Cavell suggests that, rather than refusing to take responsibility for how the practice that is taught is performed, the teacher presents him- or herself as an example and representative of the community that is engaged in the practice. ${ }^{24}$ This is in opposition to an understanding of elders as final judges for how our practices are to be performed. The only thing left for the good teacher to do is to draw the attention of the other, the dissonant child, "through accommodating herself to the singularity of her pupil. ${ }^{\prime 25}$ However, because there is nothing that teachers do or say that justifies their practice beyond doubt, no pre-given fact nor any sort of social norms, she must earn her authority to speak as a representative for the child. ${ }^{26}$ At the moment of instruction the teacher's "power comes to

23. Espen Hammer, Stanley Cavell: Scepticism, Subjectivity and the Ordinary (Cambridge: Polity Press, 2002), 65.

24. Cavell has argued that the ordinary language philosopher introduces him- or herself as an example. The ordinary language philosopher produces an example (in Wittgenstein, an "object of comparison," see PI $\S 131$ ) of an ordinary way of using a philosophically burdened concept (such as "thought," "perception," "knowledge," and the like). In doing so he or she lays out a way of doing or saying something that is to be followed. This example shows the way the ordinary language philosopher does and says things: his or her claim is that he or she does so as a representative of us. This is an invitation by the ordinary language philosopher for readers to acknowledge his or her ways as their ways. See Sanford Shieh, "The Truth of Skepticism," in Reading Cavell, ed. Alice Crary and Sanford Shieh (Oxon: Routledge, 2006).

25. Hammer, Stanley Cavell, 27.

26. Cavell, Conditions Handsome and Unhandsome, 76-78. 
an end" $(C R, 122)$. Consequently, teachers must allow their students to make sense of themselves. Mere conformity is never enough for a mutual agreement $(C R, 383)$. Children must find their own way out of the isolation of nonacceptance by their elders. Hence, just as teachers need to attract their students to their unjustified example, the dissonant students must attract their elders to see the harmony in their ways. Consequently, to come to agreement the child has the full responsibility both of making themselves and their interlocutors intelligible. The responsibility for reaching agreement with my students is mine. I should make myself intelligible and make my students intelligible to me. This acknowledgment means meeting, not half way (the metaphor of distance is of no use here), just meeting in agreement, in attunement, in harmony.

Indeed, this vision is as simple as it is terrifying. We are naturally worried about what will happen if we change our mathematical practice to fit the reactions of Wittgenstein's student, but we do not really need to change our practice, we just need to acknowledge that there are other ways to go about it and thus change ourselves. That we acknowledge the child does not mean that we do as the child does, and acknowledging seems to me difficult enough. How then, do we overcome our fears and anxieties and acknowledge the child? How are we to overcome our anxiety over whether our educational practices will end in crisis, dissonance, and disagreement? I believe that this is the question for philosophy of education. This is surely a task that deserves to be called education for grown-ups, a task and activity I call "philosophy of dissonant children."

\section{"Reading" Children, Hearing Harmony in Dissonance, and Philosophy as an Educational Conversation}

I have suggested that philosophy ought to be considered as education for grownups. Dissonant children can become teachers of our culture's criteria $(U A, 75)$. To clarify the therapeutic aspect of how a culture is found(ed) when the children work as teachers, we can turn to the style of the philosophical method of Wittgenstein as Cavell inherits it. This turn to the method is explicitly concerned with how we are to come to terms with the worries and anxieties that are intrinsic in teaching.

To Cavell, philosophy is not a set of problems to be solved, but a set of texts to be read $(C R, 3-5) .{ }^{27}$ This is not a matter of reading to be able to master the text - for example, to be able to write a good commentary on the text - or reading to be able to criticize or defend the argument of a text. Cavell talks about reading a philosophical text as challenging our self-understanding $(C R, 3-6){ }^{28}$ Reading a philosophical text should be a kind of conversation between the reader and the writer (and the text itself is a conversation with other texts). Hilary

27. See also Michael Payne, "Introduction," in Cavell, Philosophical Passages, 2; and Michael Peters, "Wittgensteinian Pedagogics: Cavell on the Figure of the Child in the Investigations," Studies in Philosophy and Education 20, no. 2 (2001): 128.

28. See also Hammer, Stanley Cavell, 30-31. 
Putnam expresses this by describing Cavell as "a writer who always speaks to individuals - and that means, one at a time." Further, Putnam exclaims that "to read Cavell as he should be read is to enter into a conversation with him, one in which your entire sensibility and his are involved, and not only your mind and his mind." 29 This means that, to read Cavell, we must not only recognize what he says, but also how he says it - philosophical content is inseparable from the presentational style. Another way to put this is to say that the purpose of the philosophical text is pedagogical; it is to teach us, its readers, to see new aspects of ourselves. This is true of Wittgenstein's Investigations. ${ }^{30}$ Wittgenstein wrote about his own text that he would not like it "to spare other people the trouble of thinking. But, if possible, to stimulate someone to thoughts of his own" $\left(P I, \mathrm{x}^{\mathrm{e}}\right.$, emphasis added). Hence, to read the Investigations is to let oneself be provoked by the multiplicity of voices in the text. As readers of the text we recognize in ourselves the temptations, impulses, and insights of the voices in the text. $I$ let the text speak representatively for me, letting the text express my temptations and impulses and thus prompt me to reflect on my own condition. Taking the text to speak for me means acknowledging the writer's ways as my own ways. Recognizing this, we also identify the voices in the Investigations that belong to dissonant children (perhaps Wittgenstein's own recalcitrant voice). The analogy between the dissonant child and the philosophical text as something that can provoke a change in our self-conceptions is evident.

The practical consequences for education, in this view of the purpose of philosophy, are that if philosophy is a set of texts to be read, then, in educational reality, this means a set of persons to be met. Accordingly, meeting and conversing with dissonant and disobedient children can be a form of philosophy of education. Instead of being a problem that we as educators have to deal with, our dissonant children's "disobedience" and our efforts to meet them in agreement may call for a revision of our cultural identities and practices. Rather than being the problem itself, the radically different assists in dissolving the problem. Because children bring our culture into imagination and help us recognize the criteria for our practices, these children stabilize the ordinary by making it visible for us. The method to treat our worry is thus, in a Cavellian spirit, to "read" our dissonant children (see $C R, 356)$. As we identify ourselves as educators and as humans, in meeting children we are engaged in teaching both our students and ourselves. This view is difficult to accept; we are not inclined to hear the harmony in what we conceive as children's dissonance. However, the therapeutic aim is to slow down the teachers' reaction, to help teachers actually listen to a child's reasons for his

29. Hilary Putnam, "Philosophy as the Education for Grownups: Stanley Cavell and Scepticism," in Reading Cavell, ed. Crary and Shieh, 119. See also Cavell, The Claim of Reason, 3-5; and Cavell, Conditions Handsome and Unhandsome, 79.

30. The idea that Wittgenstein's philosophical style is pedagogical has been argued in Michael Peters and James Marshall, Wittgenstein: Philosophy, Postmodernism, Pedagogy (London: Bergin and Garvey, 1999|, see esp. chaps. 9 and 10. 
or her behavior with the humility of a child or student, rather than to presume how the child must behave or what the child needs to know or discover. ${ }^{31}$

Since skepticism and the possibility of dissonance are part of our human condition, this therapeutic task is never final, but an ongoing education of educators. Since there is always a possibility that we will find children's behavior dissonant, there will always be a need to clarify what troubles us, and a need to be reminded of the criteria in our practices and ways of thinking. The treatments I offer the troubled educator are to listen to the radically different children we meet, and to involve our entire sensibility in conversation with these children. Peace in education comes only by reading, conversing with, and responding to one child at a time. ${ }^{32}$

31. I owe this formulation to Stanley Cavell's comment on an earlier draft of this essay (May 2008).

32. Ludwig Wittgenstein, Culture and Value (Chicago: University of Chicago Press, 1980), 44.

IN WORKING ON THIS ESSAY I benefited immensely from encouraging comments from Klas Roth. I have also benefited from, and been deeply inspired by, Naoko Saito's work on Cavell in educational contexts, in particular her The Gleam Light: Moral Perfectionism and Education in Dewey and Emerson (New York: Fordham University Press, 2005). Reading the sixth chapter of that work gave me the initial idea for this essay. I thank Niclas Rönnström, Adrian Thomasson, Paul Smeyers, Naoko Saito, and Stanley Cavell for commenting on early drafts of this text. Additionally, I thank Margie Christensen and Mary Anne Kochenderfer for proofreading the manuscript. Any remaining faults are of course my own. 